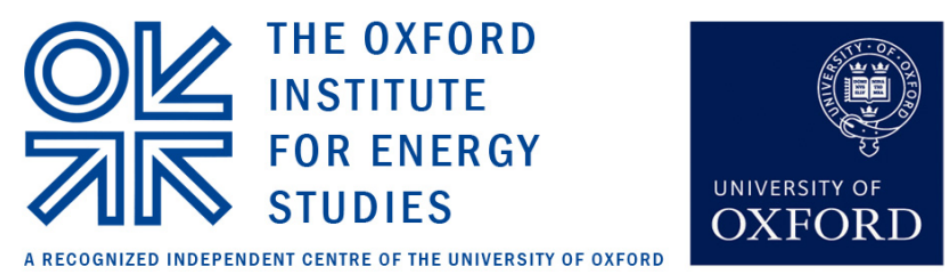

\title{
Regional Dimensions to Europe's energy integration
}

Angelique Palle*

SP 29

October 2013 
The contents of this paper are the authors' sole responsibility. They do not necessarily represent the views of the Oxford Institute for Energy Studies or any of its members.

Copyright $\odot 2013$

Oxford Institute for Energy Studies

(Registered Charity, No. 286084)

This publication may be reproduced in part for educational or non-profit purposes without special permission from the copyright holder, provided acknowledgment of the source is made. No use of this publication may be made for resale or for any other commercial purpose whatsoever without prior permission in writing from the Oxford Institute for Energy Studies.

ISBN 978-1-907555-83-1 


\section{Contents}

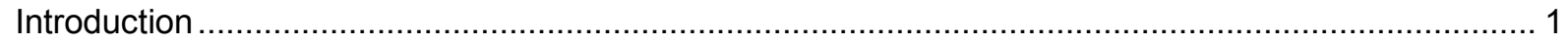

1. Integrating networks and markets - a way of enforcing current EU energy policy? ........................ 2

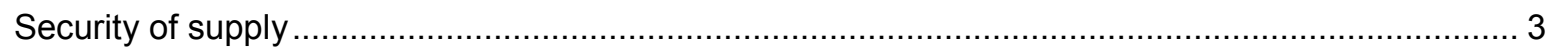

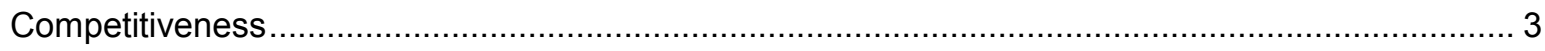

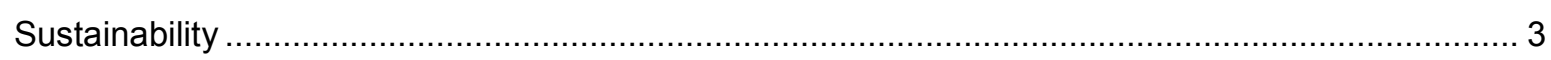

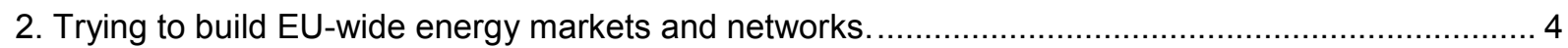

3. Adding regional rungs to the ladder of European integration ................................................... 5

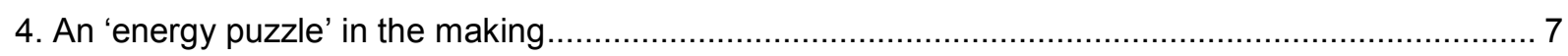

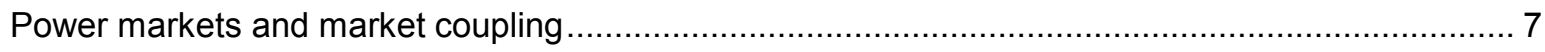

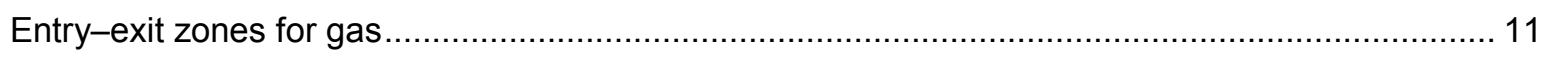

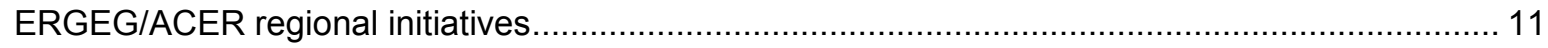

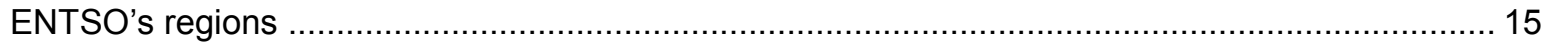

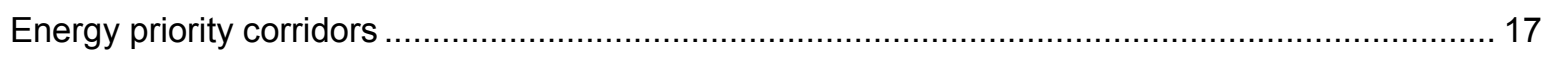

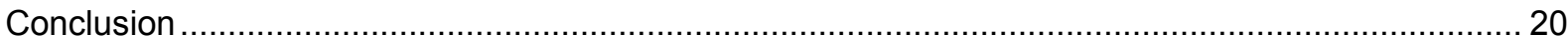

\section{Figures}

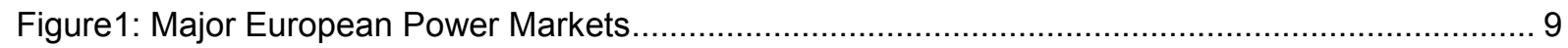

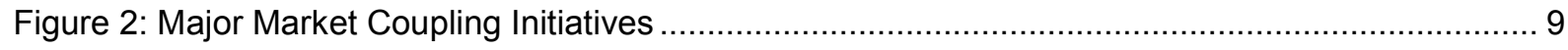

Figure 3: Weekly ratio of price convergence in the CWE region................................................. 10

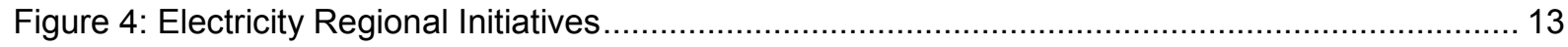

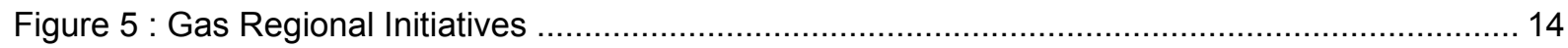

Figure 6: European Network Transmission System Operators' Regions for Gas and Electricity ......... 16

Figure 7: Priority Corridors as Defined by the European Commission ............................................ 18 


\section{Introduction}

This paper sets out to examine the regional dimension of European Union (EU) energy integration, observing how useful it has been in the past, and how effective it might be in the future.

Integration of EU-wide energy markets and networks is considered by the European Commission to be one of the best means by which the objectives of the common energy policy can be achieved. It has been working towards this goal for the last decade, attempting to build the legislative framework to complete this Internal Energy Market. This paper examines the results and the impacts of this integration strategy through the perspective of the scale (country, region, or Europe wide) at which different initiatives have taken place. Focusing on the electricity and gas industries' networks - as much of EU policy does - this paper raises the question: what is the appropriate geographical scale or level at which such integration should and can efficiently happen?

On the ground, progress towards integration seems to be more regional than EU-wide, bringing together groups of neighbouring member states with similar concerns. Regional groupings - of national regulators, transmission system operators (TSOs), and power or gas markets - were initially encouraged by the Commission. They were seen as a way to support bottom-up dynamics towards increased integration. It was supposed to be the first step towards an eventual EU-wide integrated market. Many different layers of groupings - Regional Initiatives, Priority Corridors (for infrastructure), Gas Regional Investment Plans, Electricity Regional Working Groups, and Market Coupling initiatives - have therefore been created in the last decade. These have met the Commission's expectations to some extent, acting as platforms for the development of cross-border or cooperation mechanisms and for regional testing and implementation of EU market rules. However, this energy puzzle, of different groupings with different borders for every new body or initiative, has made governance more complex. Cohesive and coherent policy making has been made more difficult given the multiplication of groupings. It is harder to analyse the amount of information produced, to know what is going on, and to monitor the interactions between all these different institutional actors, thus weakening democratic control over it.

Regional integration is a slow business in the energy sector. Building infrastructure and agreeing common codes for networks or markets are time consuming. The European Commission and Council of Ministers have grown impatient, and now want to complete the Internal Energy Market by 2014 . Why this rush? It is partly to avoid the long hiatus expected to take place in 2014 when nothing in the EU will get done, because of the changeover in the Commission and the European parliament elections - whose outcome is uncertain after almost six years of European economic crisis. It also aims to offset the current predominantly national character of renewable subsidies and capacity mechanisms, which threatens to balkanize or re-balkanize the 'single market' of $28 \mathrm{EU}$ states. This rush has taken the form of greater top-down pressure to harmonize cross-border market and trading arrangements, such as market coupling or network codes. This goes along with a tightened central 
control of the different regional initiatives. However, these more direct tactics of top-down integration cannot prevent the disruption that comes when a state like Germany decides to develop renewable energy at full speed, after abandoning nuclear power. Technical integration - building from the bottom up - cannot work if there is no political consensus in the EU or if member states do not take into account the impact of their national decisions on their neighbours.

Bottom-up regional integration efforts have, therefore, been overtaken by the drive to accelerate integration via top-down harmonization. This could lead to an impasse in integration or to a misshapen market, if the various actors on the ground (TSOs, regulators, power exchanges or gas hubs) are not yet ready or willing to advance at the level of the EU-28. Such cross-border cooperation between neighbours will, however, become increasingly important to tackle such issues as the management of renewable support schemes and capacity mechanisms, and this is where true regional cooperation and bottom-up dynamics could prove useful.

The first two parts of this paper aim to explain how the integration of energy networks and markets has been designed by the Commission as a way of enforcing EU energy policy and how, as a result, European institutions have tried over the last decade to build an EU-wide Internal Energy Market. The third part questions the impact of this strategy, as the dynamics of integration have often taken place at a regional level; it argues that the EU may not yet be ready to become a fully-fledged integrated energy market (IEM). The fourth part focuses on the different regional groupings and integration trends, which were initially supported by the Commission as bottom-up first steps towards an EU-wide market; it shows that the regional initiatives have tended to be overtaken by a more recent top-down approach aiming at rushing the integration process to achieve an EU-wide market by 2014 . This paper argues that it may be neither feasible nor desirable to skip or rush this regional phase of energy sector integration.

\section{Integrating networks and markets - a way of enforcing current EU energy policy?}

Integrating energy networks, building trans-European infrastructures, ${ }^{1}$ and creating a single and fullyintegrated energy market by 2014 is the EU's energy policy credo. Achieving integration is considered to be one of the few ways in which all three main goals of EU energy policy - security of supply, competitiveness, and sustainability - would be satisfied. But is it feasible to integrate networks and markets EU-wide now, and is it desirable?

A fourth objective - integration of energy networks and markets - might be added to the three EU energy policy goals listed above. This is both a global objective at the EU level and a means to achieve the other three goals. The EU is always keen to integrate networks at the European level.

\footnotetext{
${ }^{1}$ The Commission estimates that the current total investment requirement for energy network infrastructure is $€ 218.5 \mathrm{bn}$. European Commission, Connecting Europe, the Energy Infrastructure for Tomorrow, 2012.
} 
Liberalization and integration of road transport has been a success, work is in progress to do the same for the rail network, and it was only natural that the Commission would make the integration of energy (mainly gas and power) networks one of its goals.

Supporting the development and integration of energy networks, be it through the harmonization of the different national regulations, provision of investment incentives, or the financial support of some infrastructure projects involving two or more member states, appears a consensual way of moving towards a common European energy policy. This method of creating practical achievements is very much in line with the strategy set out by Robert Schuman, one of the EU's founding fathers, to 'build [Europe] through concrete achievements which first create a de facto solidarity' rather than 'according to a single plan'. It is creating a common EU energy policy from below in pursuit of the following goals:

\section{Security of supply}

Connecting up national energy networks and ending the isolation of 'energy islands' within Europe would help prevent disruption of supply because countries facing shortages or infrastructure breakdown could more easily draw on imports from their neighbours. As member states rely on different energy mixes, integrating the networks would also both increase the overall diversity of supply - making member states individually less dependent on one particular supplier - and favour the most cost-effective sources of energy. Some member states - those relying on Russian gas for an important part of their mix - are particularly interested in this aspect. One of the lead initiatives to improve security of supply is the Baltic Energy Market Integration Plan, launched in 2009; it involves the eight Baltic Sea Member States and aims, for example, to connect 'Finland and the three Baltic States to the European integrated gas network and new sources of supply' ${ }^{2}$ as Russia is at present the sole gas supplier to all four states.

\section{Competitiveness}

An integrated, open, transparent, and competitive EU energy market is based on physically integrated networks that should promote internal competition, favour the most cost-effective plants, and boost the development of relatively cheap renewable electricity. This would lower energy prices at a European scale, thus reinforcing the EU's industrial competitiveness.

\section{Sustainability}

Integrating energy networks at the European level is intended to create economies of scale and, when combined with the development of 'smart grid' technologies aimed at optimizing network use, to increase energy efficiency. It would encourage member states with untapped potential for renewable generation to develop and export it to the European market. For example, it is envisaged that water and wind from northern parts of the EU, and solar resources from the south, could more or less balance each other seasonally.

\footnotetext{
${ }^{2}$ Memorandum of understanding on the Baltic Energy Market Integration Plan of 17 June 2009.
} 


\section{Trying to build EU-wide energy markets and networks.}

In line with this goal of integration, which is intended to serve the common energy policy, the institutions of Europe have, for the last decade, been trying to set up a framework that would lead to the achievement of an EU-wide Internal Energy Market. The common objectives for an EU energy policy were defined in 2006 by the Commission at the request of the European Council (2005), and the true impetus for a general EU energy infrastructure policy began in 2009, when the Lisbon Treaty reaffirmed the importance of integrating energy networks, within the frame of a real 'Union policy on energy'. Through this treaty, EU energy policy gained a formal legal basis it did not previously have, and within it, the energy infrastructure policy was conceived both as a means to achieve an Internal Energy Market and as a part of the 'recovery programme' set up after the financial crisis of 2008.

For many years, the EU has sought to encourage the development of energy networks. It has progressively attempted - in 1995, 2007, and more recently 2009 - to finance, at the European level, the development of trans-European networks, ${ }^{3}$ including energy networks. Measures taken to encourage the liberalization and opening up of the electricity and gas markets in 1996 and 1998, ${ }^{4}$ adding the integration of markets to the integration of physical infrastructure networks, have been further steps toward this integration. Bodies were also created for cooperation at a European level between TSOs ${ }^{5}$ and regulators ${ }^{6}$ in 2003 and 2005.

The Third Energy Package, approved in 2009, was supposed to provide the tools to complete the liberalization of the European energy market, hampered as it still was by the market abuse potential of big vertically-integrated energy groups. The core measure of this Package was intended to weaken the market power of these biggest firms by requiring the separation of generation and distribution activities from the management of transmission networks. It was accompanied by measures to give national regulators full independence, and, to enhance regional cooperation. All these measures aimed at the integration of energy networks, guaranteeing security of supply, supporting investments in energy infrastructures and networks, and enhancing cross-border trade.

Together with these general measures, the EU has set up more specific orientations designed to select infrastructure projects of common interest that could receive financial support from the EU. 'Guidelines for trans-European energy networks' were set in 1996, 2003, 2006, and more recently

\footnotetext{
${ }^{3}$ Regulation (EC) No 67/2010 of the European Parliament and of the Council, laying down general rules for the granting of Community financial aid in the field of trans-European networks.

${ }^{4}$ Directive 96/92/EC of the European Parliament and of the Council (19 December 1996) concerning common rules for the internal market in electricity; Directive 98/30/EC of the European Parliament and of the Council (22 June 1998) concerning common rules for the internal market in natural gas.

${ }^{5}$ European Network of Transmission System Operators for Electricity (ENTSO-E) in 2003 and Gas (ENTSO-G) in 2005.

${ }^{6}$ European Regulators Group for Electricity and Gas in 2003, dissolved in 2011 when the Agency for the Cooperation of Energy Regulators (ACER), created within the framework of the third Energy Package, became operational.
} 
$2013,{ }^{7}$ when it was decided 'for the very first time that the EU [would be] co-financing the construction of large energy infrastructure from its regular budget'. ${ }^{8}$ This implemented the goals set out in the Commission's 2006 'priority interconnection plan'. ${ }^{9}$

This goal of an EU-wide, fully integrated and interconnected market, unified and planned at the European level, remains the official position of the EU institutions. In a letter to European leaders on the eve of the European Council of 22 May 2013, President Barroso reaffirmed that:

... the completion of a fully functioning, interconnected and integrated internal energy market ... is central to Europe's competitiveness and must not be fragmented.

\section{Adding regional rungs to the ladder of European integration}

The main point of this paper is to question the path this EU-wide integration strategy has taken. While the current objective of the EU is to create an energy market at the European scale, the forms of integration have often been regional. If the integration process is visualized as an ascent up a ladder towards a single European market at the top, then there are 'regional rungs' of integration that provide steps on the way up. These regional rungs involve market actors from power or gas exchanges, and also European organizations.

Many of the actors in the European energy market are seen to prefer working at a regional level with their neighbours, with whom they tend to share their concerns, rather than at an EU level where it is often difficult to define and follow common interests. The various initiatives of transmission system operators, regulators, and market players divide the EU into regional groupings, whose borders differ. Initially, the Commission encouraged these different regional initiatives. They were seen as providing the bottom-up dynamic that would complete the top-down approach undertaken by Brussels, and as building blocks constituting a 'first step' towards eventual EU-wide integration. From these regional trends might emerge not a fully integrated European market and network, but several 'energy macroregions'. They would bring together several member states, or even sub-state regions, if they had sufficient autonomy.

Part of the rationale for these macro-regions is the fact that the EU is, right now, facing an issue over the geographical scale appropriate to its energy policy. Energy is still a competence shared between the EU and member states, and this means that the principle of subsidiarity ${ }^{10}$ applies. Subsidiarity is supposed to ensure that decisions are taken at the lowest appropriate scale or level of government. The question regarding energy networks is whether the best scale really covers the whole EU, or if regional groupings would, at least for now, provide a more suitable level at which to address the challenges of the common energy policy.

\footnotetext{
${ }^{7}$ Regulation (EU) No 347/2013 of the European Parliament and of the Council (17 April 2013) on guidelines for trans-European energy infrastructure.

${ }^{8}$ Press MEMO 11/170, Brussels 19 October 2011.

9 European Commission, 2006, Priority interconnection plan COM/2006/0846 final/2.

${ }^{10}$ Defined in Article 5 of the Treaty on European Union.
} 
The concept of an optimal scale for EU energy integration is rather like asking whether there is such a thing as an 'optimum energy area' - just as there are optimum currency areas in the monetary sector. Although the theory of optimum currency areas has been widely explored since Robert Mundell and Marcus Fleming first set its terms in the 1960s (and with a renewed interest in the context of the eurozone crisis), there is currently no study or theory on what an optimum energy area would look like. The parallel, however, proves useful. One the most famous features of Mundell and Fleming's theory, the 'impossible trinity', states that a given area cannot have at the same time a fixed exchange rate, free capital movement, and an independent monetary policy; the pursuit of these three goals at the same time would lead to a crisis. Transferring this analysis to energy raises the question of whether the EU can actually aim at the same time (as it is currently doing) for: a common European energy price instead of national prices (the equivalent of a fixed exchange rate between national currencies); free energy flows (which the integration of networks is trying to achieve); and independent national energy policies for the member states, especially in relation to their energy mix and sources of supply. For example, Germany's independent energy policy regarding nuclear and renewables recently generated an electricity price decoupling with France, the Netherlands, and Belgium, leaving Poland and the Czech Republic to re-establish barriers for electricity flows at their borders.

This does not necessarily mean that EU policy is heading for an energy crisis, but it does raise the question of whether the objective of an EU-wide integrated energy area is currently within reach. A second question would relate to how the criteria for an optimum energy area could be defined. It is a difficult question to answer. Interconnection and compatible market rules must be part of these criteria. A certain size of market is also needed, to enable economies of scale. For example, the EU has defined the critical size for a gas market within its borders as 20 billion cubic metres (bcm) per annum. ${ }^{11}$ The most difficult point to settle, however, concerns both the energy mix and sources of supply of the different members composing the area. On the one hand, a somewhat similar mix and sources of supply could provide political consensus over common concerns and interests; on the other hand, very different mixes and/or sources of supply could reduce exposure to shortages and could prove complementary.

There is currently no global reflection from European institutions on this issue of an optimal scale for energy integration. Policy remains focused at the EU-wide scale. But a strange 'energy puzzle' of differing regional dimensions is emerging in Europe. Each institutional actor has its own design of groupings, in what appears to be a power game between institutions. The next part of this paper analyses the various regional groupings that make up this energy puzzle and how these regional 'bottom-up' integration initiatives are being currently eclipsed by the Commission's 'top-down' harmonization effort to complete the Internal Energy Market by 2014. It argues that rushing an immediate EU-wide integration may prove counter-productive, as it fails to encourage regional habits of cooperation which are sometimes more efficient in achieving the objectives of the common energy policy. Such habits of neighbourly cooperation could, for example, be valuable in the necessary

11 'CEER Vision for a European Gas Target Model Conclusions Paper', Ref: C11-GWG-82-03, 1 December 2011. According to estimates by Eurogas, EU's total consumption in 2012 approximates 466 bcm. 
upcoming work of regionalizing, and eventually of Europeanizing, national renewable and back-up capacity support schemes.

\section{An 'energy puzzle' in the making}

For the last ten years, the EU has been divided into a variety of regional groupings by the different actors in the energy sector. These groupings form a complex layered puzzle of overlapping pieces.

On the market side, the Nordic power market, known as NordPool, was the first regional market. It has, up to now, been a success and its creation was followed by the formation of several regional power markets or market coupling initiatives. The Commission encouraged these bottom-up initiatives, but is currently pressing them to be more complete - or more EU-wide. On the gas side, the EU market is to be divided into a certain number of entry-exit zones, according to the Gas Target Model endorsed in 2012, but these zones are not yet geographically defined. Bottom-up initiatives also appeared on the political side, led by industry and government. One example of this is the 'pentalateral group' launched in 2007 by France, Belgium, the Netherlands, Germany, and Luxembourg, while the Iberian Electricity and Gas Markets (MIBEL and MIBGAS) brought together Spain and Portugal in 2004 and 2008. Both regulators and transmission system operators have also their own groupings; these are designed with a more integrated and global approach and are under closer European control. These two types of regional initiatives have recently been taken in hand by the new Agency for Cooperation of Energy Regulators (ACER) which is driving them towards less regional and more EU-wide oriented action. However, despite its recent penchant for centralized harmonization, the Commission reverted to the use of regional groupings to implement the 2013 infrastructure regulation; trans-European interconnection projects are to be proposed by regional groups of regulators and TSOs, in a tacit admission that such groups are best suited to define Europe's network needs.

\section{Power markets and market coupling}

In terms of market integration, some 'regions' have come together with a true bottom-up dynamic. The first and best example is NordPool, which is owned by the Nordic and Baltic TSOs (see Figure 1). It stems from the joint Norwegian and Swedish power exchange established in 1995, a bilateral initiative that predates most EU policy. All the Nordic States have now joined NordPool, which is currently expanding to the Baltic states and the UK. A similar initiative is under way with the development of the Epex Spot (see Figure 1) - a power market involving Austria, France, Germany, and Switzerland which is currently trying to expand towards Hungary, the Czech Republic, and Slovakia.

Power markets are the lead actors in market coupling, which coordinates price formation mechanisms in different markets. The aim is to harmonize prices and functioning, and optimize cross-border capacity allocation. Market coupling thus paves the way for the progressive end of national power prices and the increasing emergence of 'European' power prices, leading some to dream of a single EU price for electricity. This current trend is likely to have a huge impact on national energy strategies 
and energy mixes, as the price of power is a key element of industrial and economic competitiveness, as well as being an important social issue.

The development of market coupling, again, brings forward the issue of the appropriate scale at which this initiative should be undertaken. The current goal for the Commission is to achieve a European market with a single European price, and some power markets such as Epex Spot are already modelling daily benchmarks of what this price would look like in a truly integrated European market. ${ }^{12}$ The 'scale issue' for European energy integration is an economic one which relates to building the most efficient market or combination of market designs. Economic interests are also intertwined with political ones at all levels.

Sometimes even EU institutions have competing interests. For instance, the Directorate-General for Competition and the Directorate-General for Energy may have quite opposed views, because competition is not always compatible with the construction of a single integrated market, especially as far as power exchanges are concerned. In this way, some mergers that are encouraged by DG Energy, because they allow the integration of different markets, arouse suspicion in DG Competition, because it sees in them an attempt to exert market power. An example of this relates to attempts by NordPool and Epex Spot, (the Nordic and western Europe main power markets), to set up a joint venture and start a common power exchange platform that would concentrate 50 per cent of the spot power trading in the EU (more than 90 per cent in north-west Europe, see Figure 2). This initiative is being investigated by DG Competition for anti-competitive behaviour.

However, not everyone is always interested in coupling markets, despite the pressure from Brussels. In north-west Europe there is a plan ${ }^{13}$ to couple day-ahead markets from November 2013, but intraday market coupling at this scale doesn't seem to evoke much enthusiasm. The Nordic countries already have their own integrated system and see little purpose in a costly coupling with the western part of Europe.

\footnotetext{
12 'Elix, towards a single European market price', Epex Spot web site: www.epexspot.com

${ }^{13}$ Interview with Ofgem officials, June 2013.
} 


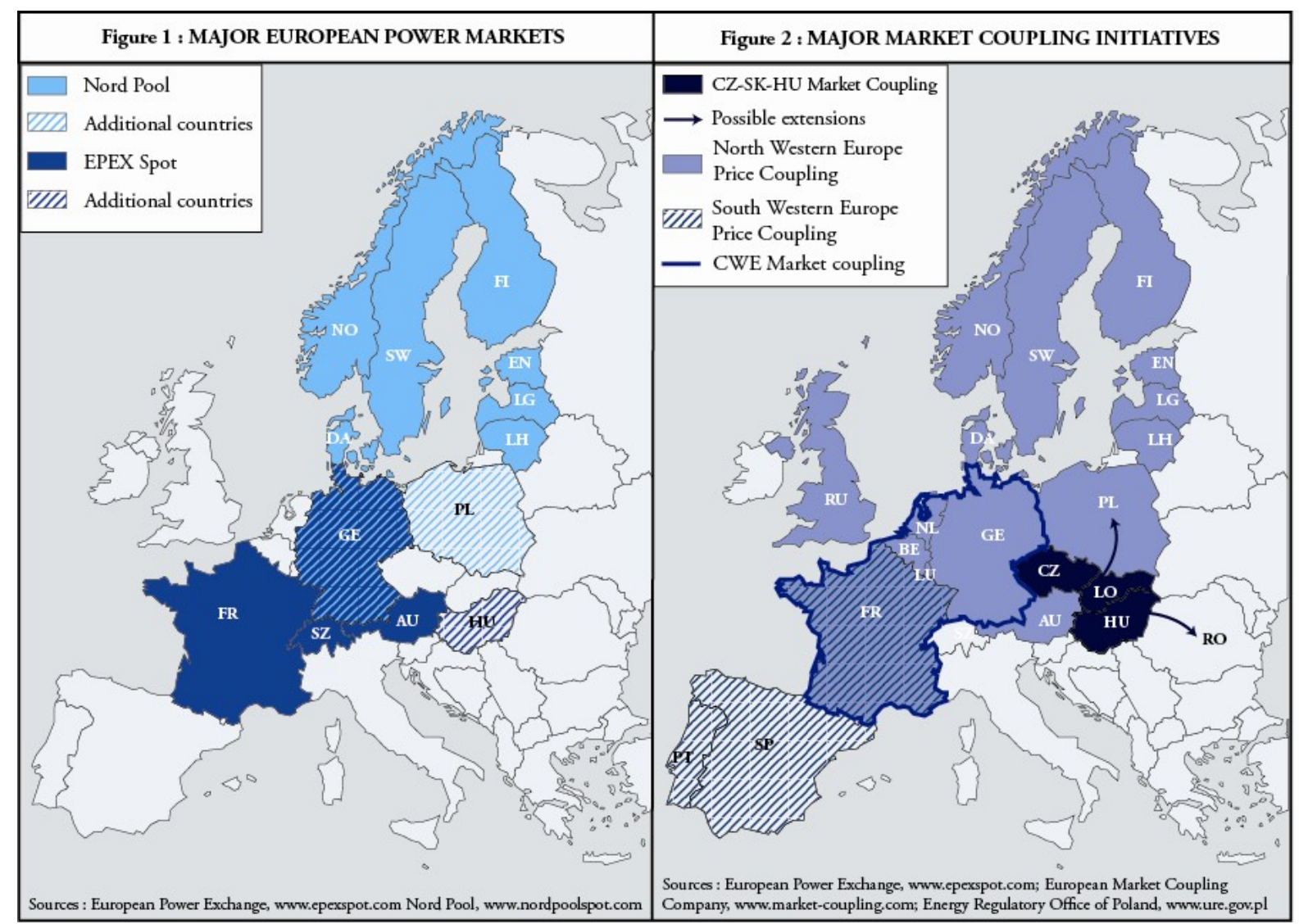

The second main issue is that even when market coupling is undertaken, prices in the two different areas do not converge if the energy mix or the energy policies of the two areas are too dissimilar. This is the current challenge facing the central-western Europe (CWE) market coupling that brings together Austria, Belgium, France, Germany, the Netherlands, and Switzerland. The main factor affecting price divergence here is the evolution of German energy policy. After CWE market coupling began in November 2010, prices converged steadily until the German decision to phase out nuclear power. Prices then decoupled between Germany and the Netherlands on one side, and France and Belgium on the other. Moreover, since the end of 2012, German prices have become increasingly disconnected from French, Belgian, and also Dutch prices, as shown in Figure 3. This is the consequence of Germany's generous subsidies to renewables and its use of cheap coal, which both stem from the triple aim of German policy to phase out nuclear power and increase the use of renewables drastically, while maintaining an electricity price that will not hamper the country's exportoriented industry.

This would not be a problem if the German power market was isolated from its neighbours. But with the CWE market coupling, Germany's neighbours see its Energiewende (energy transition) policy designed to lead Germany on the path to a greener and cleaner energy mix - as unfair competitive behaviour that effectively dumps cheap German electricity into their markets. In 2012, German exports 
of electricity were four times those of 2011. Dutch companies complained to the European Commission, which is investigating the matter. Meanwhile, the Energy Council of Ministers meeting of June 2013 ensured that Member States were reminded of the necessary:

gradual phasing out of support for new projects of certain types of maturing renewables energies when their economic viability and competitiveness have been achieved ${ }^{14}$

which is a quite explicit call for order to Germany.

Figure 3: Weekly ratio of price convergence in the CWE region

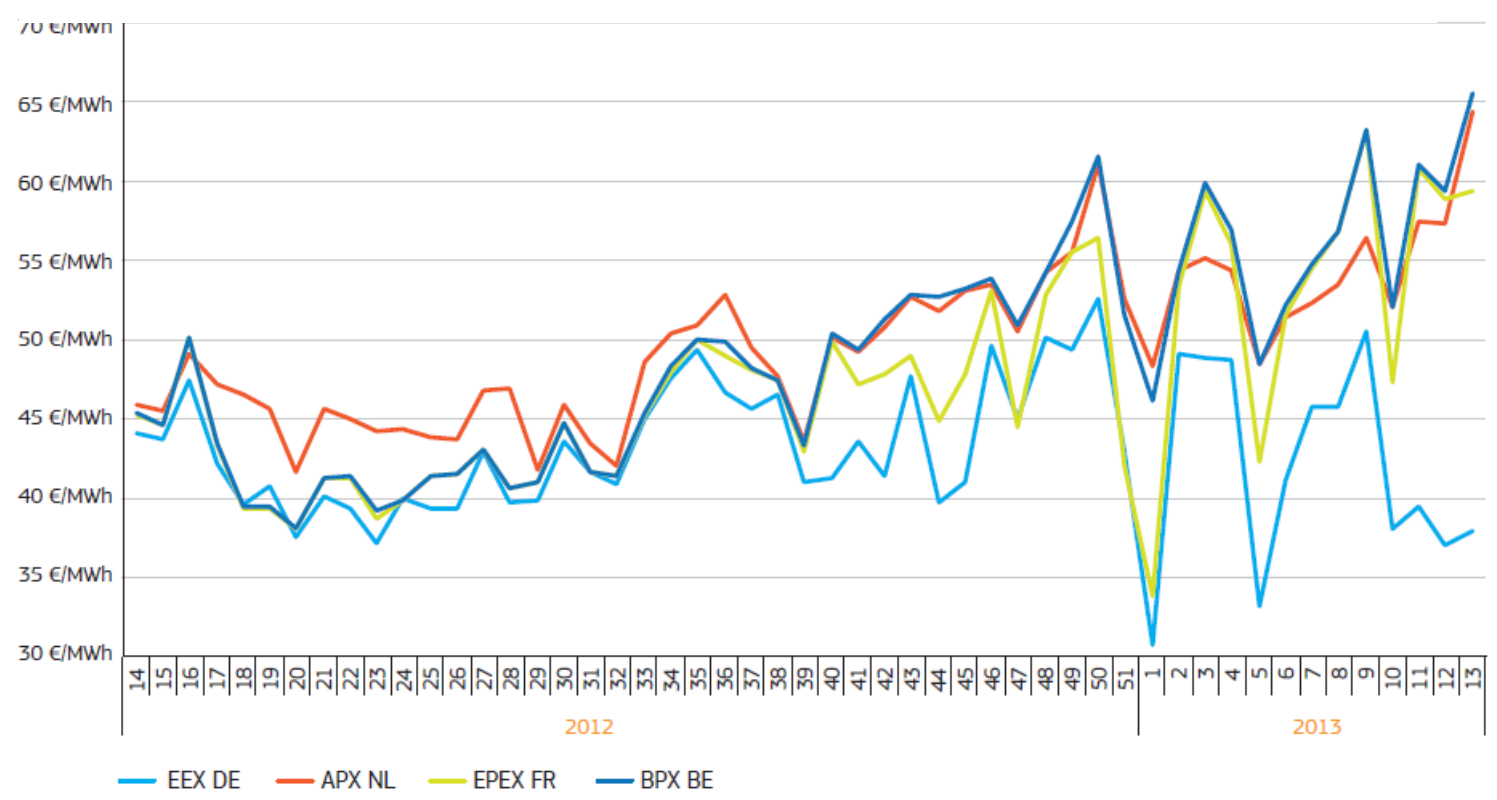

Source: Quarterly Report on European Electricity Markets, Market Observatory for Energy, DG Energy, European Commission, Volume 6, issue 1 First quarter 2013.

Germany's policy has also been attacked on its eastern border. Poland and the Czech Republic recently complained that the German energy transition was threatening the stability of their own national networks. The major centre of German consumption is located in the south of the country; with the phasing out of nuclear power, more of the electricity consumed in southern Germany has to come from the major centres of renewable power in the north. However, Germany has insufficient transmission infrastructure to carry power from north to south, and some of the power flows into the Polish and Czech networks, causing disruption. To avoid blackouts, both these countries have placed switches along their borders to enable them to disconnect their networks from the German one in case of critical overload. This is the very opposite of what the Commission is aiming for, and illustrates how rushing towards integration can be counter-productive when the technical integration of cross-border energy runs ahead of regional political consensus on energy policy. On the other hand the example of NordPool shows that bottom-up regional integration works for energy markets when the political will is there.

\footnotetext{
${ }^{14}$ Council conclusions of 6-7/10 June 2013 on the Commission Communication 'Making the internal energy market work'.
} 


\section{Entry-exit zones for gas}

The effects of entry-exit $(E E)$ zones on the gas market and the dynamic they are likely to set in train can be seen as being equivalent to the outcome for the power market resulting from market coupling. EE zones are part of the Council of European Energy Regulators' (CEER) Gas Target Model (GTM), endorsed by the 21st Madrid Forum in 2012. ${ }^{15}$ This Gas Target Model is a vision of a future single and liberalized European market 'as a combination of entry-exit zones with virtual hubs'. ${ }^{16}$ EE zones would be 'functioning wholesale markets', structured so that any gas entering the zone could be virtually delivered at any exit point in that zone; this would change the way transit costs are currently calculated for gas (on a physical route basis, defined in the contracts). The borders of the different EE zones are not yet defined, but the criteria for their definition are, the most interesting one being the standard for size. The minimum annual demand of an EE zone should be $20 \mathrm{bcm}$, mainly to ensure economies of scale.

This would imply that many member states will have to merge their own gas market with those of their neighbours, in order to attain the suitable critical size. However, it is also probable that some of the zones will cut across state borders, for geographical reasons, and encompass only parts of the different states they bring together. For example, no Austrian gas pipeline crosses the Alps and the country is likely to be divided into two zones, separated by the mountain range. ${ }^{17}$

It is too early to assess what dynamics these EE zones may create. However, as currently conceived, they will not structure the EU's gas market as an EU-wide one, but as a combination of regional markets interacting with each other. This is the only case where an analysis of the criteria to define the optimal size and borders of gas markets within the EU has been conducted, so far.

\section{ERGEG/ACER regional initiatives}

The Electricity Regional Initiative (ERI) and the Gas Regional Initiative (GRI) were launched in 2006 by the European Regulators' Group for Electricity and Gas (ERGEG) at the request of the European Commission.

As the Commissioner had said that same year there would be no new legislation on energy market liberalisation, it seemed that the only way to make progress was through the co-ordinated use of the powers of energy regulators. Consequently, the regional initiatives seemed a practical way of getting regulators and stakeholders together to discuss overcoming cross-border barriers to trade. $^{18}$

These Regional Initiatives (RI) have been conceived as being the building blocks of a subsequent fully integrated European market, a first step for integration. Each region brings together regulators, companies, member states, the European Commission, and other interested parties to focus on developing and implementing solutions to improve regional energy markets. The seven electricity

\footnotetext{
${ }^{15}$ Conclusions XXI Madrid Forum 22-23 March 2012.

16 'CEER Vision for a European Gas Target Model Conclusions Paper', Ref: C11-GWG-82-03 1 December 2011.

${ }^{17}$ See on this issue 'The EU Third Package for Gas and the Gas Target Model: major contentious issues inside and outside the EU', Katya Yafimava, Oxford Institute for Energy Studies Working Paper NG 75, April 2013, 28.

${ }^{18}$ David Halldearn, Director - Scotland and Europe, Ofgem (GB Regulator), 30 July2013.
} 
regional initiatives (Figure 4) have, up to now, stayed the same shape since their creation, but the possibility of reshaping one of the current three gas ones has been discussed (Figure 5).

The Commission evaluated the results of the RIs in $2010^{19}$ and stated that they were positive overall. However, it also stated that, although the design of electricity regions had proven quite effective, for gas the south-south-east region was too heterogeneous and its member states' interests too disparate. This hampered both its efficiency and the engagement of the parties. The Commission therefore concluded that this region should be divided into more homogeneous areas. This redefinition is interesting because it implies that some features effectively 'predispose' an area to become an 'energy region' and that a certain degree of homogeneity would be one of the features needed for cooperation to function.

Moreover, the Commission also noted that the definition of different regions resulted in them all having somewhat different approaches to EU policy, even though the involvement of some countries in several regional groups had been supposed to bring more coherence to the overall work. ${ }^{20}$

From 2006 to 2011, the different Regional Initiatives focused on regional issues. Each region had its own targets and orientations in line with its size, its geographical position within the EU, and the different challenges it faced. For example in electricity, the Baltic region's roadmap focused, besides integration within the Baltic states, on the region's potential 'to function as the link between the centraleast and the northern European regional markets' ${ }^{21}$ Its main priorities were to address transparency issues, to enhance cooperation between network operators, to promote grid access, and to set up balancing rules. The central-east region (Austria, the Czech Republic, Germany, Hungary, Poland, Slovakia, and Slovenia), on the other hand, focused more on the integration of old and new EU members. Its main concerns were the management of congestion and the reduction of barriers to market entry, along with the development of regulatory competences and of transparency.

During this period, the Regional Initiatives carried and supported many projects which related to the objectives of the common energy policy, in both gas and electricity. They ranged from the creation of cross-border reverse-flow capabilities on unidirectional pipelines in the south-south-east gas region to improve security of supply, to a harmonization of the transparency requirements in six electricity regions. Other regional achievements were attained in capacity calculation, capacity allocation and congestion management, balancing or interoperability, and hub development. ${ }^{22}$

\footnotetext{
${ }^{19}$ Communication from the Commission to the European Parliament and the Council on the future Role of Regional Initiatives COM/2010/0721 final. 20 lbid.

21 CEER, ERI Baltic Region, www.energy-regulators.eu.

22 CEER and ERGEG, 2010, Fact Sheet, The Regional Initiatives - a major step towards integrating Europe's national energy markets.
} 
Figure 4: Electricity Regional Initiatives

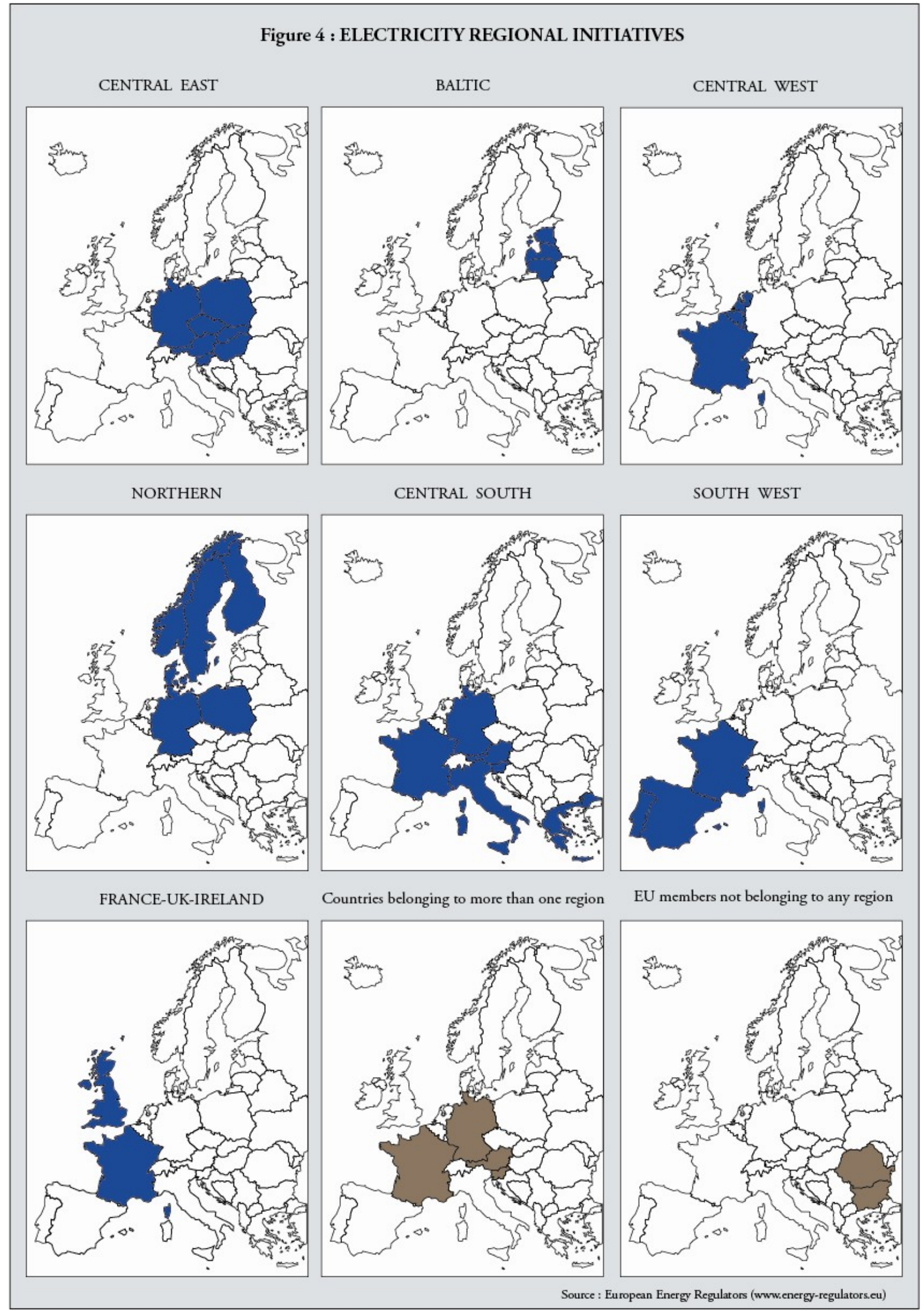


Figure 5 : Gas Regional Initiatives

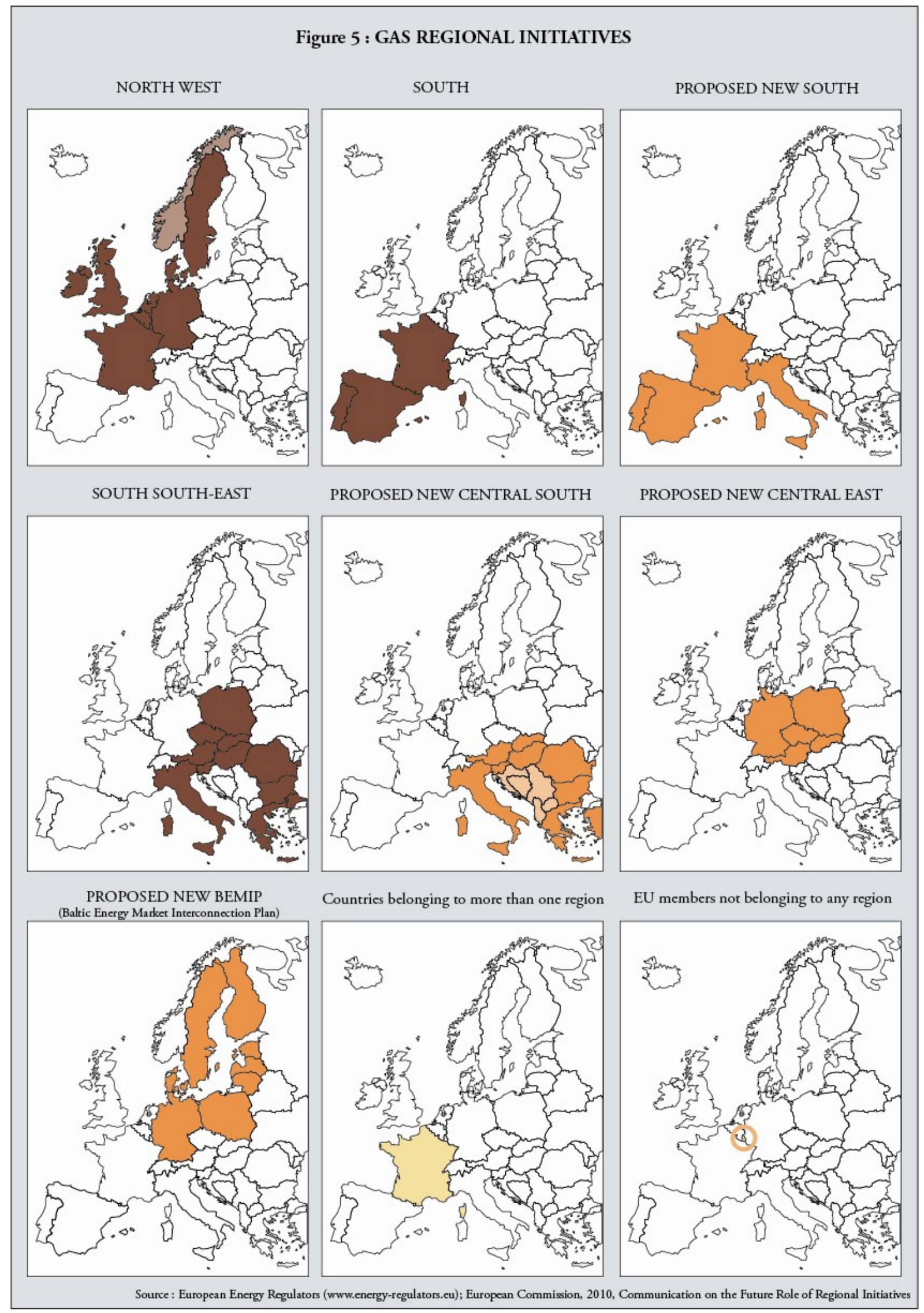


After the entry into force of the Third Energy Package, the newly created Agency for Cooperation of Energy Regulators (ACER) took over the Regional Initiatives from ERGEG in 2011, with the ambitious goal, set by the European Council of February 2011, of completing the Internal Energy Market by $2014 .^{23}$ The objective was no longer for each region to focus on its own regional integration and issues through bottom up-dynamics. ACER's 'new approach' concerning Regional Initiatives is mainly to ensure their 'coordination, ${ }^{24}$ and to act as an overall supervisor. The individual objectives that were set by each region for itself were replaced by:

... a more project-oriented and pan-European approach, with notably the development of crossregional roadmaps, as a way to guarantee that Regional Initiatives will deliver progress towards the IEM. $^{25}$

This switch of emphasis appeared to be partly because the Regional Initiatives were viewed as having advanced far enough for progress to a wider level of integration to proceed ${ }^{26}$ but also because the initiatives were seen as too regional and not sufficiently European-oriented, in light of the new 2014 target date. ${ }^{27}$

It also has to be said that, in the European context, most national regulators like to exchange views with their neighbouring counterparts as and when they need to. ${ }^{28}$ Some of these regulators considered the Regional Initiatives monitored by Brussels as having too rigid a framework for informal crossborder consultations. For example in the France-UK-Ireland Electricity Regional Initiative, Ireland and the UK currently face an issue of system compatibility but do not see the point of involving France in negotiations that do not affect the French power system, even if this type of issue falls under the competences of the Regional Initiative of which they are all part. Moreover, important initiatives - such as the Pentalateral Energy Forum, launched in 2007, which brings together the governments, regulators, and TSOs of Belgium, France, Germany, Luxembourg, and the Netherlands - have taken place at a regional level in parallel with, and outside of, the defined Regional Initiatives. But ACER's new approach towards more EU-wide goals and control is even less flexible, and may further empty the Regional Initiatives of useful content.

\section{ENTSO's regions}

The Transmission System Operators also set up their own groupings. The foundation of the current associations of European TSOs - the European Networks of Transmission System Operators for gas (ENTSO-G) and electricity (ENTSO-E) - accompanied the Third Energy Package and the goal of completing the Internal Energy Market. Both ENTSO-E and ENTSO-G have divided the EU into several regions within the framework of their investment plans. There is here no explicit match between gas and electricity regions (see Figure 6).

\footnotetext{
${ }^{23}$ Conclusions on Energy, European Council, 4 February 2011.

${ }^{24}$ ACER Regional Initiatives Status Review Report 2012.

${ }^{25}$ ACER Regional Initiatives Status Review Report 2011, Getting to 2014: the role of Regional Initiatives.

${ }^{26}$ Interview with DG ENER officials, May 2013.

${ }^{27}$ Interview with Ofgem officials, June 2013.

28 Ibid.
} 
The EU requires European gas TSOs to promote regional cooperation ${ }^{29}$ through Gas Regional Investment Plans (GRIPs) published biennially and 'based on an analysis of transmission system interconnections and operation, as well as infrastructure development needs'. ${ }^{30}$ They are supposed to be a regional bridge between the EU-wide Ten Year Network Development Plan and the national plans. The first GRIPs, released in 2011 and 2012, are too new for their impact to be analysed.

Figure 6: European Network Transmission System Operators' Regions for Gas and Electricity

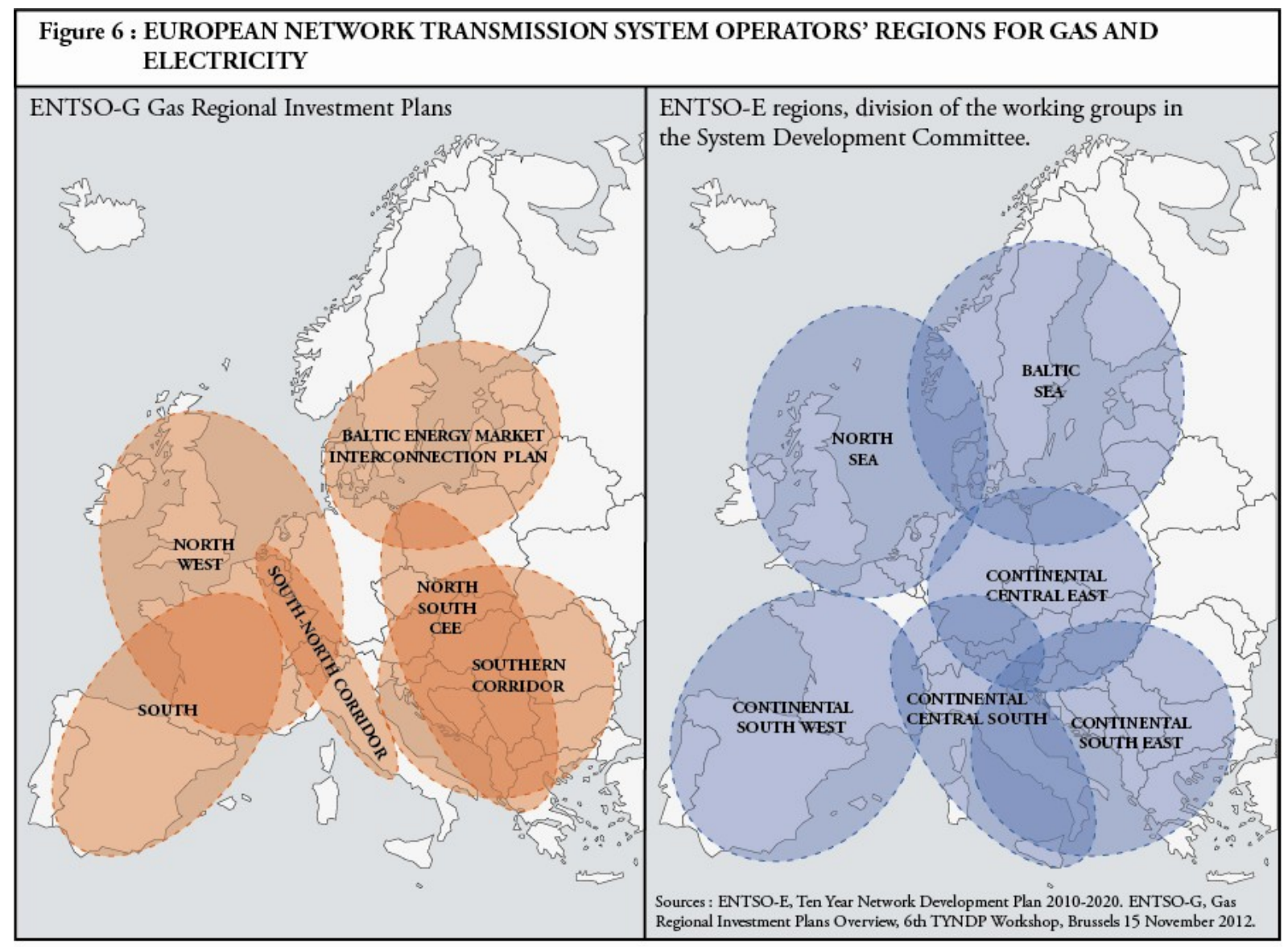

For its part, ENTSO-E has directly integrated its regional division of the EU into its Ten Year Network Development Plan (TYNDP). This was first released in 2010 and has since been updated every two year. The regions are designed as 'main investment clusters' with a specific focus on integration of renewable energy into the electricity market, regional power balances, new power flows, and reinforcement of urban distribution systems. ENTSO-E's System Development Committee, which is in charge of cooperation, is divided into working groups according to these regions. ENTSO-E presented

\footnotetext{
${ }^{29}$ Directive 2009/73/EC of the European Parliament and of the Council (13 July 2009) concerning common rules for the internal market in natural gas, and Regulation (EC) No 715/2009 of the European Parliament and of the Council (13 July 2009) on conditions for access to the natural gas transmission networks.

${ }^{30}$ ENTSOG web site, www.entsog.eu.
} 
its second TYNDP in 2012. This drew comments from ACER ${ }^{31}$ that information which appeared in different regional plans needed to be harmonized. The agency's main critique was that cooperation and consistency between integration efforts at regional and European levels were not as seamless as they ought to be.

\section{Energy priority corridors}

In line with the objective of completing the Internal Energy Market by 2014, the European Parliament and the Council adopted the trans-European energy infrastructure regulation on the development of trans-European energy networks in spring $2013 .^{32}$ This identifies:

... twelve priority corridors that must be implemented in the coming decade to help the EU meet its short and longer term energy and climate objectives.

Energy infrastructure projects meeting this goal can be labelled as 'Project of Common Interest' (PCI) and benefit from accelerated permit granting procedures and possible EU funding. Of these twelve 'corridors', four concern gas and four others electricity, one is for oil and the last three are thematic ones (smart grids, $\mathrm{CO}_{2}$ networks, and electricity highways). Three of the electricity corridors are matched with gas ones to cover the same area (Figure 7, second, third, and fourth maps). The shape of these 'energy priority corridors' is in fact more that of regions than of actual corridors.

Regional groups have been formed, each covering a Priority Corridor as set out in Annex I to the regulation. ${ }^{33}$ They are composed of the member states, national regulators, project promoters, and other relevant stakeholders and they will be in charge of establishing the regional lists of proposed priority corridors.

31 Opinion of the Agency for the Cooperation of Energy Regulators N ${ }^{\circ}$ 06/2012 (5 September 2012) on the European Ten-Year Network Development Plan 2012.

32 Regulation $N^{\circ} 347 / 2013$ of the European Parliament and of the Council (17 April 2013) on guidelines for trans-European energy infrastructure and repealing Decision No 1364/2006/EC and amending Regulations (EC) No 713/2009, (EC) No 714/2009 and (EC) No 715/2009. 33 Ibid. 
Figure 7: Priority Corridors as Defined by the European Commission

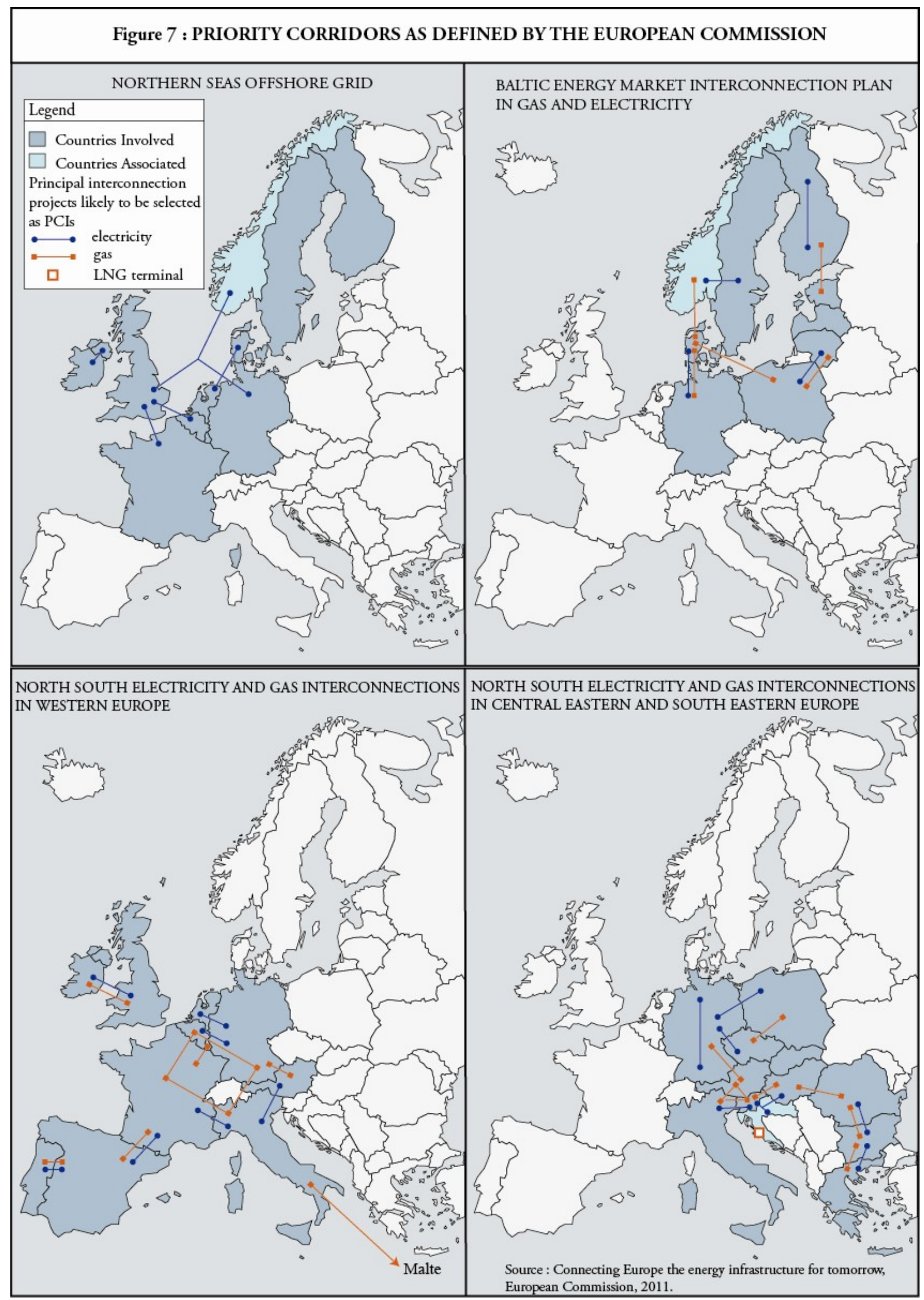




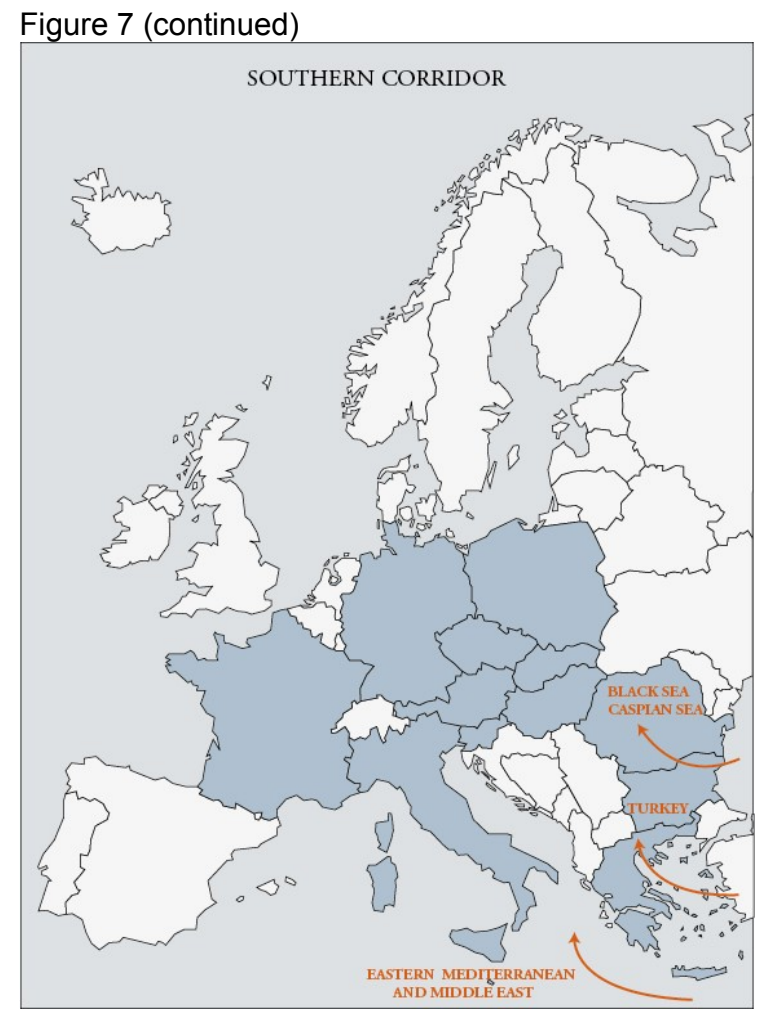

The regional groups formed to select the Priority Corridors differ from both the groupings formed under the Regional Initiatives led by ACER and the different regional working groups within ENTSO-E and ENTSO-G (introduced in the previous section and discussed further below). The design of these regional groups seems to have been decided despite the wishes of the national regulators, ${ }^{34}$ who lobbied for a design that would match the groupings already in place through the Regional Initiatives, pleading that the appropriate structures were already in place and that efficiency in the decision making process would be enhanced if a matching design was used. One of the justifications for variable geometry in energy market integration is that different groupings have different purposes and objectives in terms of time scale. ${ }^{35}$ The Regional Initiatives monitored by ACER are focused on the upcoming 2014 objective to complete the Internal Energy Market. ENTSO-E and ENTSO-G's working groups have a short-term perspective, dealing with current issues of cooperation, while the regional groups covering the Priority Corridor areas have a long-term perspective, promoting projects whose completion is likely to extend over a decade or more.

Interestingly, in establishing the list of potential priority corridor projects, the Commission still resorted to dividing the EU into regional groupings, even though it is trying elsewhere (in its dealings with ACER and the ENTSO organizations) to rush through the regional integration phase to arrive at a more EU-wide oriented structure. This must reflect a view that, in practice, regional groupings are best placed to judge 'trans European' projects such as cross-border PCls, which are de facto regional projects.

\footnotetext{
${ }^{34}$ Interview with Ofgem officials, June 2013.

35 Interview with DG ENER officials, May 2013.
} 


\section{Conclusion}

The Commission is obsessed with immediate and complete integration of the IEM, first because it seems an easy way to achieve the three goals of the common energy policy, second because it sees integration as good in itself, and third because it feels that time is running out before the political deadline of 2014. The question this paper is asking is whether this strategy is the most efficient. On the ground, all the actors (TSOs, regulators, market operators) have a tendency to work at a regional level in their cooperation and even the Commission itself appears to be thinking regionally in its latest projects. This is reflected by the multiplicity of regional initiatives and groupings; each type of institutional actor has its own vision of how the groupings should be formed, thus building an 'energy puzzle' made of different layers.

The Commission first encouraged regional integration as a building block towards an EU-wide edifice, but it is now trying to rush the process to the next step, to meet its political objective. This focus on the formal goal, more than on the process itself and on its consequences, could prove counter-productive.

In terms of legislation and network codes, the EU is likely to achieve completion of the single market by 2014. But on the TSO side, the perception seems to be that the EU is, in its haste, storing up trouble for the future. Some regulators and TSOs suggest that they may well be implementing in 2014 the market that would have been suitable for $2008,{ }^{36}$ saying that they are already preparing future amendments to some of the Network Codes. ${ }^{37}$

On the regulator side, the national authorities seem, for now, to be more willing to cooperate at a regional level than at the European one. The European Regulator, ACER, was established in 2010 and is still considered to be a young body, which has been entrusted with very important competences regarding the monitoring of network development and the cooperation of both TSO and national regulators, along with the strategic definition of the Framework Guidelines (for network codes). It will take a few more years yet before it acquires the experience, information, and governance needed to completely and accurately fulfil its competences. Its new approach - to steer the Regional Initiatives towards more pan-European objectives, as requested by the Commission - might transform these initiatives into empty shells if the national regulators, who considered that Regional Initiatives were already too rigid a framework, are no longer interested in cooperating within this structure and prefer to function outside it.

Regarding markets, some of the power market coupling initiatives have been successful. However, the recent effects of German energy policy shifts on the CWE market coupling have also proven that this type of technical integration has to be matched by a political cooperation and consensus if it is to achieve its goals. Rushing technical integration is, to some extent, useless if the politicians cannot come up with some elements of common policy. This also goes for gas in the EE zones.

\footnotetext{
${ }^{36}$ Interview with RTE officials, March 2013.

${ }^{37}$ Interview with Ofgem officials, June 2013
} 
The Commission itself, even while putting more top-down pressure on all regional groupings for increased EU-wide integration, reverted to regional groupings when it came to its latest project 'priority corridors' for infrastructure.

Integration cannot be just a purpose in itself; it has to serve other goals. The top-down approach will be ineffective if it does not have the support of the different European energy actors. These seem, for now, to be more inclined to respond to regional dynamics, where a real common interest exists between neighbours. These dynamics have proven to be efficient in many cases. Some initiatives, like the north-west Europe day-ahead market coupling, which brings together half of the member states, transcend the regional, but they can only happen when there is a real purpose for the parties behind them.

There are new and pressing issues, such as the national management of renewable support schemes or of capacity mechanisms that risk fragmenting the European energy sector. Rather than these schemes being managed nationally, the Commission would prefer to see them run on at least a regional basis (if harmonization at an EU level is not possible). But solutions cannot come solely from a top-down technical approach, reacting after every country has already set up its own capacity mechanism or its own policy on support for renewables. The Commission may therefore come to regret its failure to foster regional cooperation in other areas of energy policy. 